\title{
Heat Transfer Enhancement In a Ribbed Duct
}

\author{
J.M. Jalil*, T.K. Murtadha, H.M. Kadom \\ Educational Technology Department, University of Technology, P.O. Box 35010, Baghdad, Iraq
}

Received 26 May 2004; accepted 21 March 2005

تحسين انتقال المراره في هبرى ذو عوائق

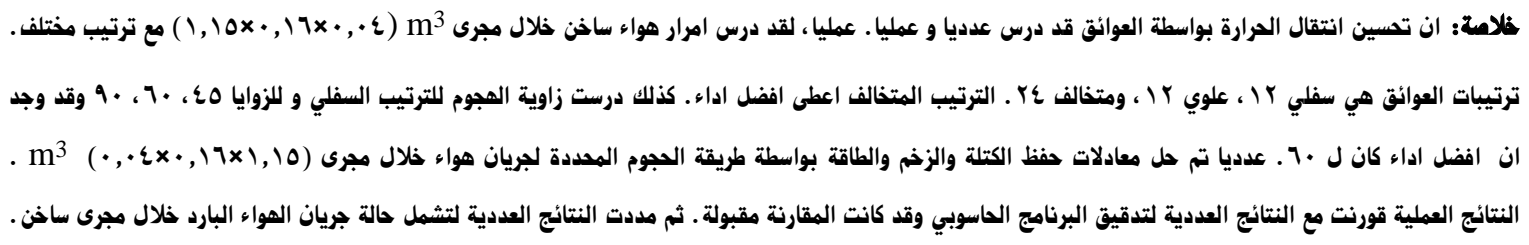

\begin{abstract}
The rib enhancement of heat transfer in a duct is studied numerically and experimentally, where hot air passes through a duct $\left(0.04 \times 0.16 \times 1.15 \mathrm{~m}^{3}\right)$ with different rib arrangement. The arranments are lower 12-rib arrangement; upper 12 rib arrangement and 24 rib staggered arrangement. The staggered arrangement gives better performance than the others. Also, the angle of attack was studied for lower arrangement, three different values were tested $\left(45^{\circ}, 60^{\circ}\right.$ and $\left.90^{\circ}\right)$. Angle of $60^{\circ}$ gives better performance. Numerically, the three-dimension continuity, Navier-Stokes and energy equations are solved by finite volume method of flow of air through $\left(0.04 \times 0.16 \times 0.6 \mathrm{~m}^{3}\right)$. Validation of the code was performed by comparing the numerical result with the results obtained experimentally for staggered arrangement only. The agreement seems acceptable. The numerical studies were extended to study the case of cold air passing through hot ribbed duct.
\end{abstract}

Keywords: CFD, Heat transfer enhancement, Finite volume

\section{Notation}

\section{Symbol}

$\mathrm{a}_{\mathrm{B}}, \mathrm{a}_{\mathrm{E}}, \mathrm{a}_{\mathrm{F}}, \mathrm{a}_{\mathrm{N}}, \mathrm{a}_{\mathrm{S}}, \mathrm{a}_{\mathrm{W}}=$ coefficients in general finite-volume equation

$\mathrm{C}_{\mu}, \mathrm{C}_{1 \varepsilon}, \mathrm{C}_{2 \varepsilon} \quad=$ constants in turbulence model

$\mathrm{D}_{\mathrm{h}}, \quad=$ hydraulic diameter, $\mathrm{m}$

g = gravitational acceleration, $\mathrm{m} / \mathrm{s}^{2}$

$\mathrm{H}_{\mathrm{r}}, \mathrm{W}_{\mathrm{r}} \quad$ = rib height and width, $\mathrm{mm}$

$\mathrm{H} \quad$ = height of the duct, $\mathrm{m}$

$\mathrm{i}, \mathrm{j}, \mathrm{k}=$ position indices for the $\mathrm{x}$-, and $\mathrm{y}$, and $\mathrm{z}$-directions

$\mathrm{I}_{\mathrm{u}} \quad=$ turbulence intensity

*Corresponding author’s e-mail: jalaljalil@yahoo.com 


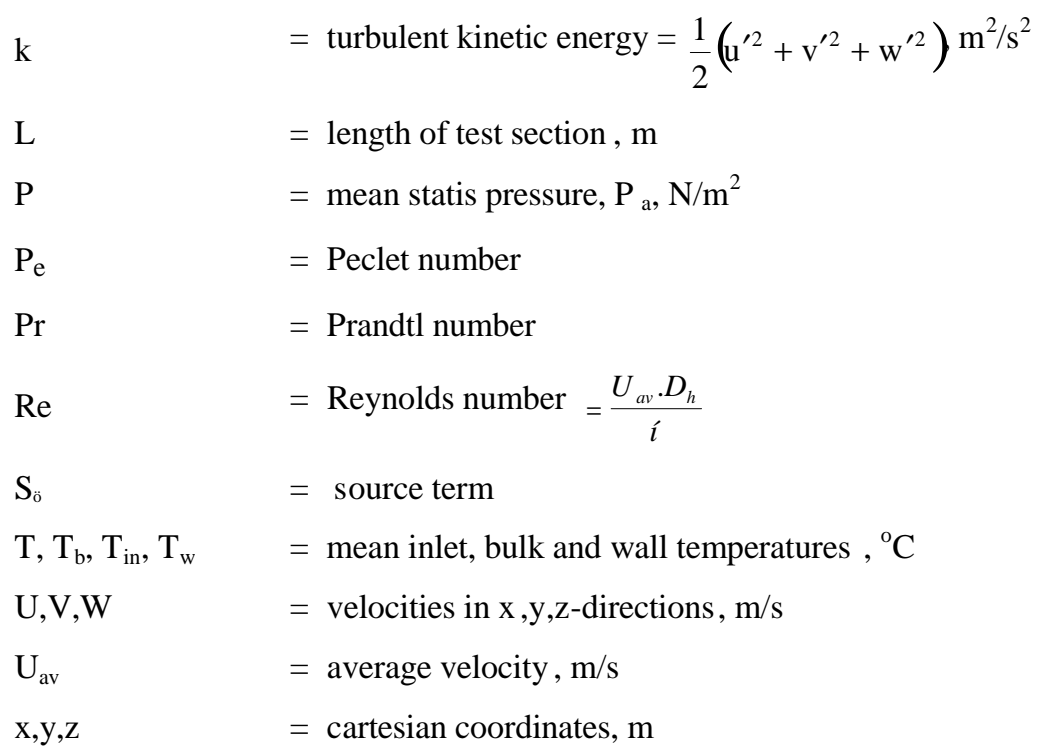

\section{Greek Symbols}

$\begin{array}{ll}\varepsilon & =\text { dissipation rate of turbulent kinetic energy } \\ \rho & =\text { density of air, } \mathrm{kg} / \mathrm{m}^{3} \\ \sigma_{\mathrm{k}}, \sigma_{\varepsilon} & =\text { turbulent Prandtl numbers for } \mathrm{k} \text { and } \varepsilon \\ \mu & =\text { dynamic viscosity, } \mathrm{N} . \mathrm{s} / \mathrm{m}^{2} \\ \nu & =\text { kinematic viscosity, } \mathrm{m}^{2} / \mathrm{s} \\ v_{\mathrm{t}} & =\text { eddy or turbulent viscosity }, \mathrm{m}^{2} / \mathrm{s} \\ \nu_{\mathrm{e}} & =\text { effective kinemat ic viscosity, } \mathrm{m}^{2} / \mathrm{s} \\ \Gamma & =\text { diffusion coefficient, } \Gamma=\mu / \sigma, \mathrm{N} . \mathrm{s} / \mathrm{m}^{2} \\ \Gamma_{\mathrm{e}} & =\text { effective diffusion coefficient, } \Gamma=\mu_{\mathrm{e}} / \sigma_{\mathrm{e}}, \mathrm{N} . \mathrm{s} / \mathrm{m}^{2} \\ \phi & =\text { general dependent variable }\end{array}$

\section{Introduction}

Rib turbulator has numerous applications in practical engineering systems where it is used in internal cooling passages of modern gas turbine blades that must be protected from hot gas streams. Thus, the accurate prediction of the characteristics of the flow field in these regions is of great importance. Ribs on channel walls can increase heat transfer coefficients in the cooling passages. These ribs which are called turbulators, increase the level of mixing of the cooler air with the warmer air close to channel wall, thereby enhancing the cooling capability of the passage through compressing the coolant flow rate.

The rib turbulator was studied extensively in recent years experimentally and numerically. Experimentally, different techniques were used to evaluate the aerodynamic of fluid flow and heat transfer. Han (1988) studied the effect of the channel aspect ratio on the distribution of the local heat transfer coefficient in rectangular channels with two opposite ribbed walls (to simulate turbine airfoil cooling passages). Taslim, et al. (1996) used a liquid crystal technique to measure heat trsnsfer coefficients in twelve test sections with square and trapezoidal cross sectional areas representing blade mid-chord cooling cavities in a modern gas turbine. Gao and Sunden (2001) used liquid crystal thermography in the heat transfer experiment to demonstrate detailed temperature distribution between a pair of ribs on ribbed surfaces. Lee and Moneim (2001) examined heat transfer and flow behavior on a horizontal surface with a two-dimensional transverse rib using a CFD model. Kim and Kim (2001) performed numerical optimization coupled with Reynolds-averaged NavierStokes analysis of flow and heat transfer for the design of rib-roughened surface.

Raisee and Bolhasani (2003) investigated the fluid flow and heat transfer through ducts roughened by arrays of either attached or detached ribs. the numerical approach used in this work is the finite-volume method. Hadhrami and Han (2003) studied the effect of various $45^{\circ}$ angledrib turbulator arrangements. Chang, et al. (2004) presented an experimental study of heat transfer in a rectangular channel with two opposite walls roughened by $45^{\circ}$ staggered ribs swinging about two orthogonal axes under single and compound modes of pitching and rolling oscillations. Tanda (2004), used repeated ribs on heat exchange surfaces to promote turbulence and enhance convective 
heat transfer. Onbasioglu and Huseyin (2004) used a liquid crystal based experimental investigation of heat transfer enhancement by ribs on a vertical plate.

In this work, a duct roughened with ribs was investigated numerically and experimentally. In both cases, the effect of rib turbulator on fluid flow and heat transfer was studied and analyzed.

\section{Mathematical Model}

The governing equations are: (Patanker, 1980) Continuity,

$$
\frac{\partial U}{\partial x}+\frac{\partial V}{\partial y}+\frac{\partial W}{\partial z}=0
$$

Navier Stokes,

$$
\begin{gathered}
\frac{\partial \mathrm{U}^{2}}{\partial \mathrm{x}}+\frac{\partial \mathrm{UV}}{\partial \mathrm{y}}+\frac{\partial \mathrm{UW}}{\partial \mathrm{z}}=-\frac{1}{\rho} \frac{\partial \mathrm{P}}{\partial \mathrm{x}}+\frac{\partial}{\partial \mathrm{x}}\left(v_{\mathrm{e}} \frac{\partial \mathrm{U}}{\partial \mathrm{x}}\right) \\
+\frac{\partial}{\partial \mathrm{y}}\left(v_{\mathrm{e}} \frac{\partial \mathrm{U}}{\partial \mathrm{y}}\right)+\frac{\partial}{\partial \mathrm{z}}\left(v_{\mathrm{e}} \frac{\partial \mathrm{U}}{\partial \mathrm{z}}\right) \\
+\frac{\partial}{\partial \mathrm{x}}\left(v_{\mathrm{e}} \frac{\partial \mathrm{U}}{\partial \mathrm{x}}\right)+\frac{\partial}{\partial \mathrm{y}}\left(v_{\mathrm{e}} \frac{\partial \mathrm{V}}{\partial \mathrm{x}}\right)+\frac{\partial}{\partial \mathrm{z}}\left(v_{\mathrm{e}} \frac{\partial \mathrm{W}}{\partial \mathrm{x}}\right) \\
\frac{\partial \mathrm{UV}}{\partial \mathrm{x}}+\frac{\partial \mathrm{V}^{2}}{\partial \mathrm{y}}+\frac{\partial \mathrm{WV}}{\partial \mathrm{z}}=-\frac{1}{\rho} \frac{\partial \mathrm{P}}{\partial \mathrm{y}}+\frac{\partial}{\partial \mathrm{x}}\left(v_{\mathrm{e}} \frac{\partial \mathrm{V}}{\partial \mathrm{x}}\right) \\
+\frac{\partial}{\partial \mathrm{y}}\left(v_{\mathrm{e}} \frac{\partial \mathrm{V}}{\partial \mathrm{y}}\right)+\frac{\partial}{\partial \mathrm{z}}\left(v_{\mathrm{e}} \frac{\partial \mathrm{V}}{\partial \mathrm{z}}\right) \\
+\frac{\partial}{\partial \mathrm{x}}\left(v_{\mathrm{e}} \frac{\partial \mathrm{U}}{\partial \mathrm{y}}\right)+\frac{\partial}{\partial \mathrm{y}}\left(v_{\mathrm{e}} \frac{\partial \mathrm{V}}{\partial \mathrm{y}}\right)+\frac{\partial}{\partial \mathrm{z}}\left(v_{\mathrm{e}} \frac{\partial \mathrm{W}}{\partial \mathrm{y}}\right) \\
\frac{\partial \mathrm{UW}}{\partial \mathrm{x}}+\frac{\partial \mathrm{VW}}{\partial \mathrm{y}}+\frac{\partial \mathrm{W}}{\partial \mathrm{z}}=-\frac{1}{\rho} \frac{\partial \mathrm{P}}{\partial \mathrm{z}}+\frac{\partial}{\partial \mathrm{x}}\left(v_{\mathrm{e}} \frac{\partial \mathrm{W}}{\partial \mathrm{x}}\right) \\
+\frac{\partial}{\partial \mathrm{y}}\left(v_{\mathrm{e}} \frac{\partial \mathrm{W}}{\partial \mathrm{y}}\right)+\frac{\partial}{\partial \mathrm{z}}\left(v_{\mathrm{e}} \frac{\partial \mathrm{W}}{\partial \mathrm{z}}\right) \\
+\frac{\partial}{\partial x}\left(v_{e} \frac{\partial U}{\partial z}\right)+\frac{\partial}{\partial y}\left(v_{e} \frac{\partial V}{\partial z}\right)+\frac{\partial}{\partial z}\left(v_{e} \frac{\partial W}{\partial z}\right)
\end{gathered}
$$

Also the energy equation:

$$
\begin{array}{r}
\frac{\partial \mathrm{UT}}{\partial \mathrm{x}}+\frac{\partial \mathrm{VT}}{\partial \mathrm{y}}+\frac{\partial \mathrm{WT}}{\partial \mathrm{z}}=\frac{\partial}{\partial \mathrm{x}}\left(\Gamma_{\mathrm{e}} \frac{\partial \mathrm{T}}{\partial \mathrm{x}}\right) \\
+\frac{\partial}{\partial \mathrm{y}}\left(\Gamma_{\mathrm{e}} \frac{\partial \mathrm{T}}{\partial \mathrm{y}}\right)+\frac{\partial}{\partial \mathrm{z}}\left(\Gamma_{\mathrm{e}} \frac{\partial \mathrm{T}}{\partial \mathrm{z}}\right)
\end{array}
$$

To solve the governing Eqs. (1)-(5), mathematical expressions for effective kinematic viscosity, $v_{\mathrm{e}}$, and effective diffusion coefficient, $\Gamma_{\mathrm{e}}$, are required through use of a turbulence model.
The standard $k-\varepsilon$ model (Launder and Spalding) has two equations, one for $k$ and one for $\varepsilon$. It uses the following transport equations for $k$ and $\varepsilon$.

$$
\begin{gathered}
\frac{\partial}{\partial \mathrm{x}}(\mathrm{kU})+\frac{\partial}{\partial \mathrm{y}}(\mathrm{kV})+\frac{\partial}{\partial \mathrm{z}}(\mathrm{kW})=\frac{\partial}{\partial \mathrm{x}}\left(\frac{\mathrm{v}_{\mathrm{t}}}{\sigma_{\mathrm{k}}} \frac{\partial \mathrm{k}}{\partial \mathrm{x}}\right) \\
+\frac{\partial}{\partial \mathrm{y}}\left(\frac{\mathrm{v}_{\mathrm{t}}}{\sigma_{\mathrm{k}}} \frac{\partial \mathrm{k}}{\partial \mathrm{y}}\right)+\frac{\partial}{\partial \mathrm{z}}\left(\frac{\mathrm{v}_{\mathrm{t}}}{\sigma_{\mathrm{k}}} \frac{\partial \mathrm{k}}{\partial \mathrm{z}}\right)+\mathrm{G}-\varepsilon \\
\frac{\partial}{\partial \mathrm{x}}(\varepsilon \mathrm{U})+\frac{\partial}{\partial \mathrm{y}}(\varepsilon \mathrm{V})+\frac{\partial}{\partial \mathrm{z}}(\varepsilon \mathrm{W})=\frac{\partial}{\partial \mathrm{x}}\left(\frac{\mathrm{v}_{\mathrm{t}}}{\sigma_{\varepsilon}} \frac{\partial \varepsilon}{\partial \mathrm{x}}\right) \\
+\frac{\partial}{\partial \mathrm{y}}\left(\frac{\mathrm{v}_{\mathrm{t}}}{\sigma_{\varepsilon}} \frac{\partial \varepsilon}{\partial \mathrm{y}}\right)+\frac{\partial}{\partial \mathrm{z}}\left(\frac{\mathrm{v}_{\mathrm{t}}}{\sigma_{\varepsilon}} \frac{\partial \varepsilon}{\partial \mathrm{z}}\right)+\mathrm{C}_{1 \varepsilon} \frac{\varepsilon}{\mathrm{k}} \mathrm{G}-\mathrm{C}_{2 \varepsilon} \frac{\varepsilon^{2}}{\mathrm{k}} \\
\mathrm{G}=\mathrm{v}_{\mathrm{t}}\left[2\left(\frac{\partial \mathrm{U}}{\partial \mathrm{x}}\right)^{2}+2\left(\frac{\partial \mathrm{V}}{\partial \mathrm{y}}\right)^{2}+2\left(\frac{\partial \mathrm{W}}{\partial \mathrm{z}}\right)^{2}\right. \\
\left.+\left(\frac{\partial \mathrm{V}}{\partial \mathrm{y}} \frac{\partial \mathrm{U}}{\partial \mathrm{x}}\right)^{2}+\left(\frac{\partial \mathrm{V}}{\partial \mathrm{z}} \frac{\partial \mathrm{W}}{\partial \mathrm{x}}\right)^{2}+\left(\frac{\partial \mathrm{V}}{\partial \mathrm{z}} \frac{\partial \mathrm{W}}{\partial \mathrm{y}}\right)^{2}\right]
\end{gathered}
$$

where $\varepsilon$, is the dissipation term. The parametric values in this study are given in Table 1 .

Table 1. Empirical constants in the k- $\varepsilon$

\begin{tabular}{|l|l|l|l|l|}
\hline $\mathrm{C}_{\mu}$ & $\mathrm{C}_{1 \varepsilon}$ & $\mathrm{C}_{2 \varepsilon}$ & $\sigma_{\mathrm{k}}$ & $\sigma_{\varepsilon}$ \\
\hline 0.09 & 1.44 & 1.92 & $\begin{array}{l}1.0 \\
0\end{array}$ & 1.30 \\
\hline
\end{tabular}

The general partial differential equation has the form:

$$
\begin{aligned}
& \frac{\partial}{\partial x}(\rho U \phi)+\frac{\partial}{\partial y}(\rho V \phi)+\frac{\partial}{\partial z}(\rho W \phi)=\frac{\partial}{\partial x} \\
& \left(\Gamma_{\phi} \frac{\partial \phi}{\partial x}\right)+\frac{\partial}{\partial y}\left(\Gamma_{\phi} \frac{\partial \phi}{\partial y}\right)+\frac{\partial}{\partial z}\left(\Gamma_{\phi} \frac{\partial \phi}{\partial z}\right)+S_{\phi}
\end{aligned}
$$

where the three terms on the lefthand side are convection terms and the four terms on the righthand side are diffusion and source terms. The source term appearing in the above governing equation is given in Table 2 .

\section{Experimental Investigation}

In this study, flow in rectangular channel with rib turbulator was investigated experimentally for different air bulk velocities of 4.2, 5.8, 8.2 and $10 \mathrm{~m} / \mathrm{s}$. Figure 1 shows the rib locations along the duct for five arrangements. Figure 2 shows a schematics of the experimental apparatus. The test duct has a cross section of $160 \times 40 \mathrm{~mm}^{2}$ with a corresponding hydraulic diameter, $\mathrm{D}_{\mathrm{h}}=64 \mathrm{~mm}$, and a length of $18 D_{h}$. The side walls of the entire test duct were made of plexiglas plates to provide optical access for measurements. 

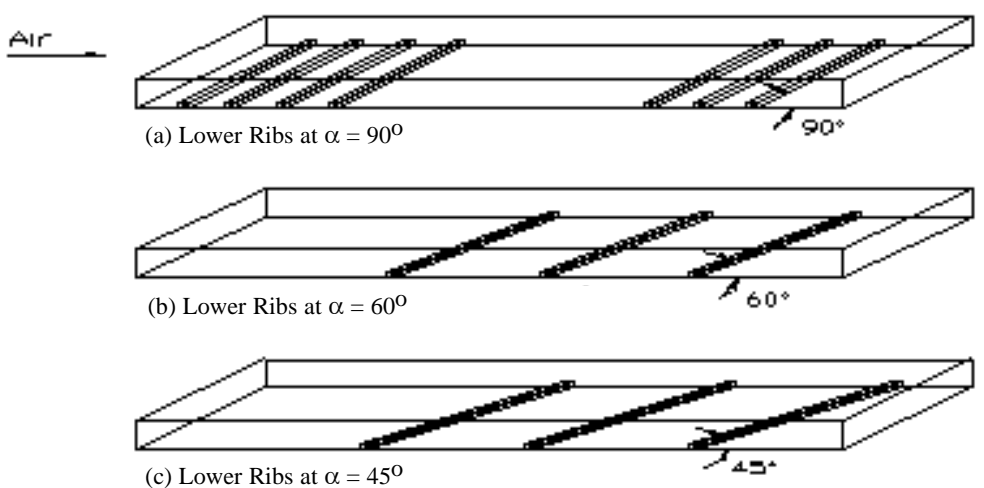

(c) Lower Ribs at $\alpha=45^{\circ}$
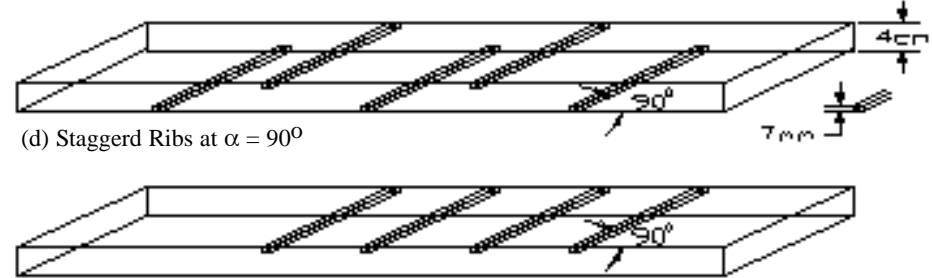

(e) Upper Ribs at $\alpha=90^{\circ}$

Figure 1. Rib locations along the duct

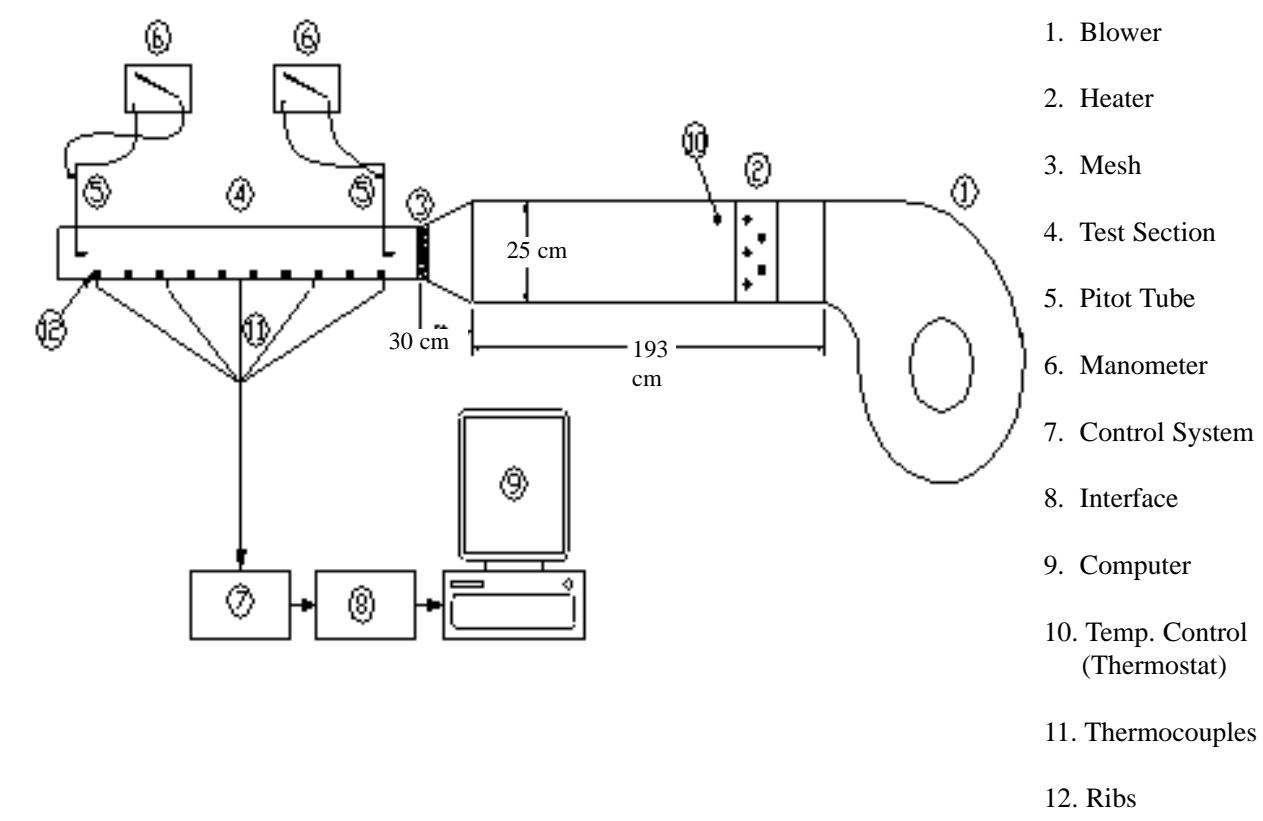

Figure 2. Schematic drawing of the overall experimental system 
Table 2. Source term in the governing (PDES)

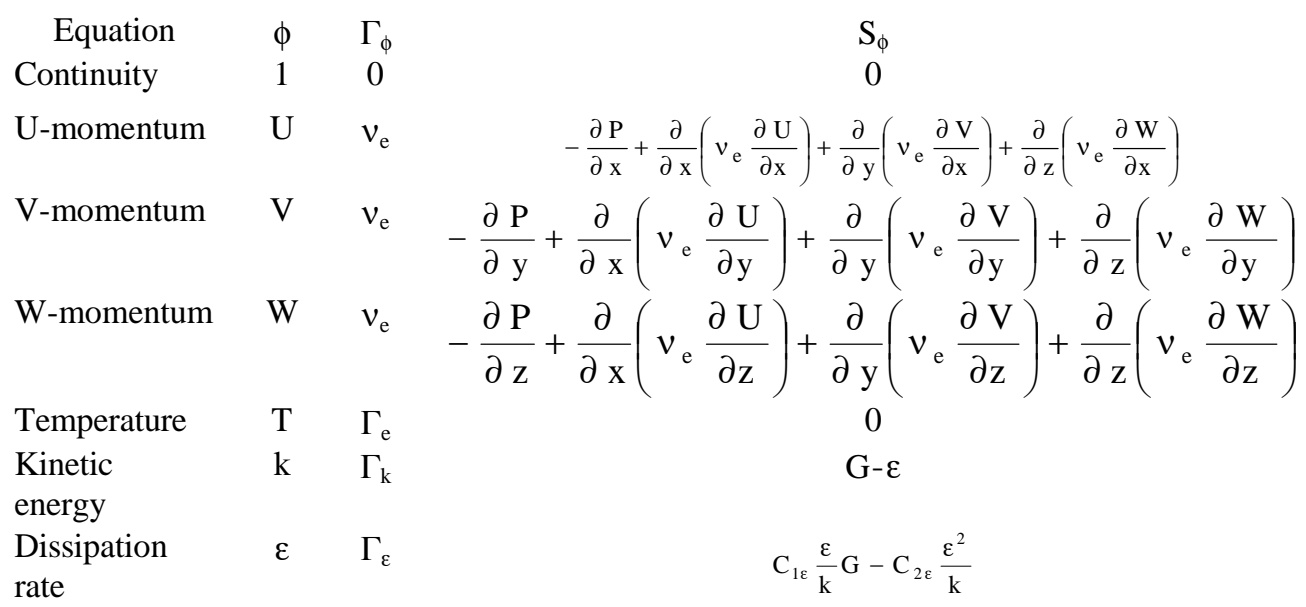

The top and bottom are made from steel sheets. The plexiglas rectangular ribs of $5.2-\mathrm{mm}$ width, $6.8-\mathrm{mm}$ height were positioned along the duct at twelve stations.

Five arrangements were tested:

1. Lower wall ribs with $\alpha=45^{\circ}$.

2. Lower wall ribs with $\alpha=60^{\circ}$.

3. Lower wall ribs with $\alpha=90^{\circ}$.

4. Upper wall ribs with $\alpha=90^{\circ}$.

5. Staggered arrangement where the ribs are positioned in lower and upper walls with $\alpha=90^{\circ}$.

Temperature distribution at various locations in longitudinal and lateral directions was measured using insulated copper-constantan thermocouple wire type $\mathrm{T}(0.27$ $\mathrm{mm}$ ). The rib turbulators were placed on opposite walls with angles of $45^{\circ}, 60^{\circ}, 90^{\circ}$. Twelve rectangular ribs were tested in this investigation where rib height to duct hydraulic diameter ratio $(\mathrm{e} / \mathrm{H})$ is 0.106 and rib width to hydraulic diameter is 0.078 . The rib turbulators were rectangular cross section rods $\left(\mathrm{H}_{\mathrm{r}}=6.8 \mathrm{~mm}\right.$ and $\left.\mathrm{W}_{\mathrm{r}}=5 \mathrm{~mm}\right)$. The inlet flow to the duct was heated to specified temperatures and the local temperatures were measured in lateral and longitudinal directions using fifty thermocouples: twenty-five thermocouples for measuring the temperature of the flow and twenty-five for measuring the surface temperature of the channel.

\section{Results and Discussions}

\subsection{Experimental Results}

Forty tests were carried out. Four values of inlet velocities are studied (4.2, 5.8, 8.2 and $10 \mathrm{~m} / \mathrm{s}$ ) with two different inlet temperatures of 40 and $50^{\circ} \mathrm{C}$.

In the experimental work, the hot air with controlled temperature enters the duct with ribs. The temperature of the air decreases all the way to the end of the duct because of the heat transfer from hot air to the duct wall which will be enhanced due to turbulence effect of ribs. This enhancement in heat transfer, usually, is accompanied with additional pressure drop.

To study the effect of different angles of attack, three angles were tested $45^{\circ}, 60^{\circ}$ and $90^{\circ}$. In $90^{\circ}$, higher pressure drops are expected. The differences in pressure drop are explained as follows, in $90^{\circ}$ the flow of air will be stopped completely in front of rib while in $60^{\circ}$, the rib allows the air in front of the rib to turn and take side passage, parallel to the rib. In $45^{\circ}$, easier passage for air is allowed parallel to the rib. The high pressure drops at $90^{\circ}$ are not necessarily accompanied by higher heat transfer. In $60^{\circ}$ and $45^{\circ}$ angles, the heat transfer will be higher due to longer ribs. The rib lengths are $16 \mathrm{~cm}$ for lower $90^{\circ}$, $18.5 \mathrm{~cm}$ for lower $60^{\circ}$ and $22.7 \mathrm{~cm}$ for lower $45^{\circ}$. The longer ribs with angle of attack will have two advantages over the short $90^{\circ}$ rib. First it causes lower pressure drop, which is the main parameter in fluid flow design. the second advantage is that, the larger rib means higher turbulence effect of consequently higher heat transfer enhancement. The only disadvantage is that longer rib means more material and higher cost. The effect of different angles of attack on heat transfer performance was evaluated through the temperature difference. The high temperature difference means high advantage gain from rib arrangement. Angle $60^{\circ}$ seems to be the best value. Han (1988) also mentions the same for optimum value of angle of attack for rib arrangement. Four different inlet air velocities were tested: $4.2,5.8,8.2$ and $10 \mathrm{~m} / \mathrm{s}$. This is achieved through changing the power supply to the fan.

Due to limitation of heating equipment, only two different inlet air temperatures of $40^{\circ}$ and $50^{\circ}$ were used. This was done by changing the power supply to the heater working elements. Clearly, the higher inlet air temperatures lead to higher air and wall temperatures along the duct. 


\subsection{Validation of the Code}

The first run of the computer program was for the condition similar to the experimental arrangement where hot air going through the duct and the wall temperature was calculated in addition to air temperature by conduction. One case was tested to compare the results with experimental part. The test case is staggered ribs with $90^{\circ}$, inlet air velocity $4.2 \mathrm{~m} / \mathrm{s}$, inlet air temperature $40^{\circ} \mathrm{C}$. Only half length of the duct was simulated by computer program, with 12 ribs in staggered arrangement for half duct only $(\mathrm{L}=0.6 \mathrm{~m})$ with same cross section area as in experimental part $(0.4 \mathrm{~m} \times 0.16 \mathrm{~m})$. Figure 3a shows the velocity vector field, Figure $3 \mathrm{~b}$ shows the isotherm contours. For isotherm contours, the high temperature is shown at inlet and it decreases with very low rate toward the walls and rib. For comparison with experimental results, the air and wall temperatures are compared and good agreement was achieved between the two.

\subsection{Numerical Results}

The numerical part will be devoted to different physical conditions. Usually in most papers, cold air passes through isothermal higher temperature duct walls which we chose to follow.

In this part, air with different velocities (2.5, 5, 7.5 and $10 \mathrm{~m} / \mathrm{s}$ ) are passed through a duct similar to experimental part where the cross section is $0.16 \times 0.04 \mathrm{~m}^{2}$ with a length of $0.6 \mathrm{~m}$ (half the experimental duct). The air inlet temperature was fixed at $20^{\circ} \mathrm{C}$ and the wall plus rib temperatures were fixed at $40^{\circ} \mathrm{C}$. Number of ribs are 6 for lower and upper arrangements, and 12 for staggered arrangement. Three arrangements were tested, staggered, lower and upper. Five heights of ribs were tested, 3, 4, 5, 6 and $7 \mathrm{~mm}$.

Figure 4 presents the distribution of three - dimensional flow field in staggered case for $\mathrm{Re}=25000$ and $\mathrm{Hr}=7$ $\mathrm{mm}$. It can be seen from the figure that the introduction of ribs locally reduces the cross section resulting in a main flow acceleration around these obstacles. The sudden expansion downstream of the ribs leads to a separation zone behind them, after reattachment the entrained flow builds up a new boundary layer. The latter is accelerated by the mainstream through shear forces and impinges on the next rib. The flow deflection around the ribs is responsible for high - velocity vectors, finally indicating the existence of third small vortex on the top of the ribs.

In contour figures, the three-dimensional plot of isotherm contours are plotted for only three levels in zdirection, one near the right wall and second at mid of the duct and the third near the left wall. The air enters with temperature of $20^{\circ} \mathrm{C}$ and the temperatures of the walls of the duct and ribs are isothermal at $40^{\circ} \mathrm{C}$. Temperature of the air increases through the duct from $20^{\circ} \mathrm{C}$ at inlet to $40^{\circ} \mathrm{C}$ at the walls. The increase in air temperature depends on many factors. The main one is the existence of ribs will work in two different ways; first as surface area with temperature of $40^{\circ} \mathrm{C}$. This point was eliminated in experimental part where the ribs are made of Plexiglass; but in numerical calculation, the ribs will work as surface area. Second the turbulence effect of ribs will increase the heat transfer. The other parameter that increases the air temperature was the rib height. As the height increases, increased area and work and more turbulence is expected. The third parameter is the inlet air velocity. As the inlet velocity increases, less time is available for heat transfer. Then the decrease in inlet air velocity will increase the temperature of air through the duct. Finally, the kind of arrangement of ribs will affect the process of heat transfer. Figure 5 shows the contours for lower arrangement at constant velocity $2.5 \mathrm{~m} / \mathrm{s}$ with different rib heights $3,4,6$ and $7 \mathrm{~mm}$. The effect of rib height is clear as the lead to higher air temperatures.

The air bulk temperatuee increase as ribs, ribs with higher air velocity decreases. Figure 6 shows the variation of air bulk temperature at constant air velocity of 5 $\mathrm{m} / \mathrm{s}$ and different rib heights of 3, 4, 5, 6 and $7 \mathrm{~mm}$ : the higher temperatures at higher heights.

The average Nusselt number for each of four walls at each $\mathrm{x}$ position, can be calculated by, right wall,

$$
\mathrm{Nu}=\int_{0}^{\mathrm{L}} \frac{(1-\mathrm{T}(\mathrm{i}, \mathrm{j}, \mathrm{k}))}{\mathrm{dx}} \mathrm{dy}
$$

For lower ribs with $90^{\circ}$, Fig. 7 shows plots for fourinlet air velocities. Each plot shows the variation of Nusselt number with duct length. Higher Nu results with high rib height. The final correlation equation for air (at constant Prandtl number) for each arrangement is:

$$
\mathrm{Nu}=\mathrm{a} \mathrm{Re}^{\mathrm{b}} \mathrm{x}^{\mathrm{C}} \mathrm{Hr}^{\mathrm{d}}
$$

The values of constants are given in Table 3:

Table 3 The values of constants in Eq. (11)

$\begin{array}{lcccc}\begin{array}{l}\text { Rib } \\ \text { arrange- } \\ \text { ment }\end{array} & \text { a } & \text { b } & \text { c } & \text { d } \\ \text { Lower } & 1.478088 & 0.243154 & -0.296225 & 0.004205 \\ \text { Upper } & 1.974745 & 0.329244 & -0.240705 & 0.033619 \\ \text { Stagge Red } & 4.061650 & 0.272817 & -0.203860 & 0.118233\end{array}$

\section{Conclusions and Recommendations}

The following are concluded:

1. Increasing rib height enhances the Nusselt number.

2. High Reynolds number enhances the Nusselt number.

3. The optimum angle of attack was $60^{\circ}$ for heat transfer enhancement. 

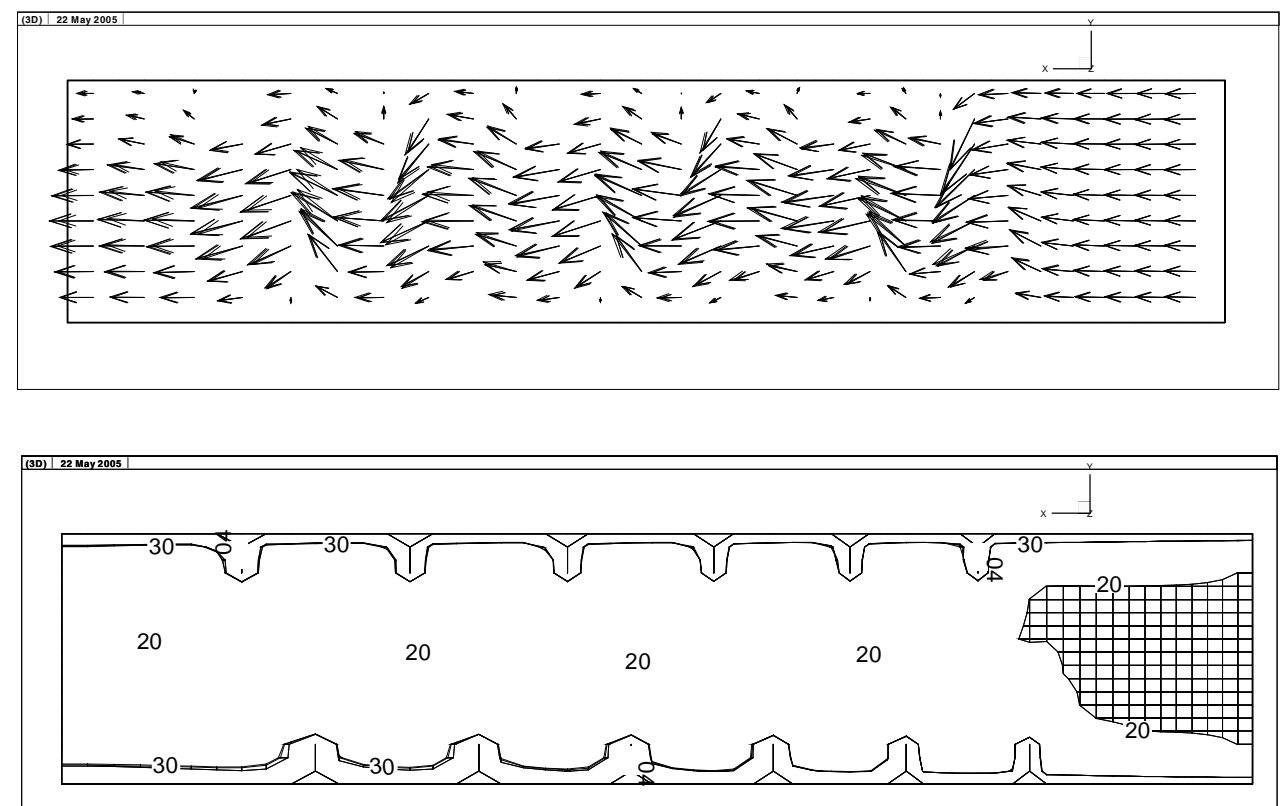

Figure 3. Velocity vector field and isotherm contours along the duct with staggered ribs, $v=7.5 \mathrm{~m} / \mathrm{s}$ and $H_{r}=3 \mathrm{~mm}$

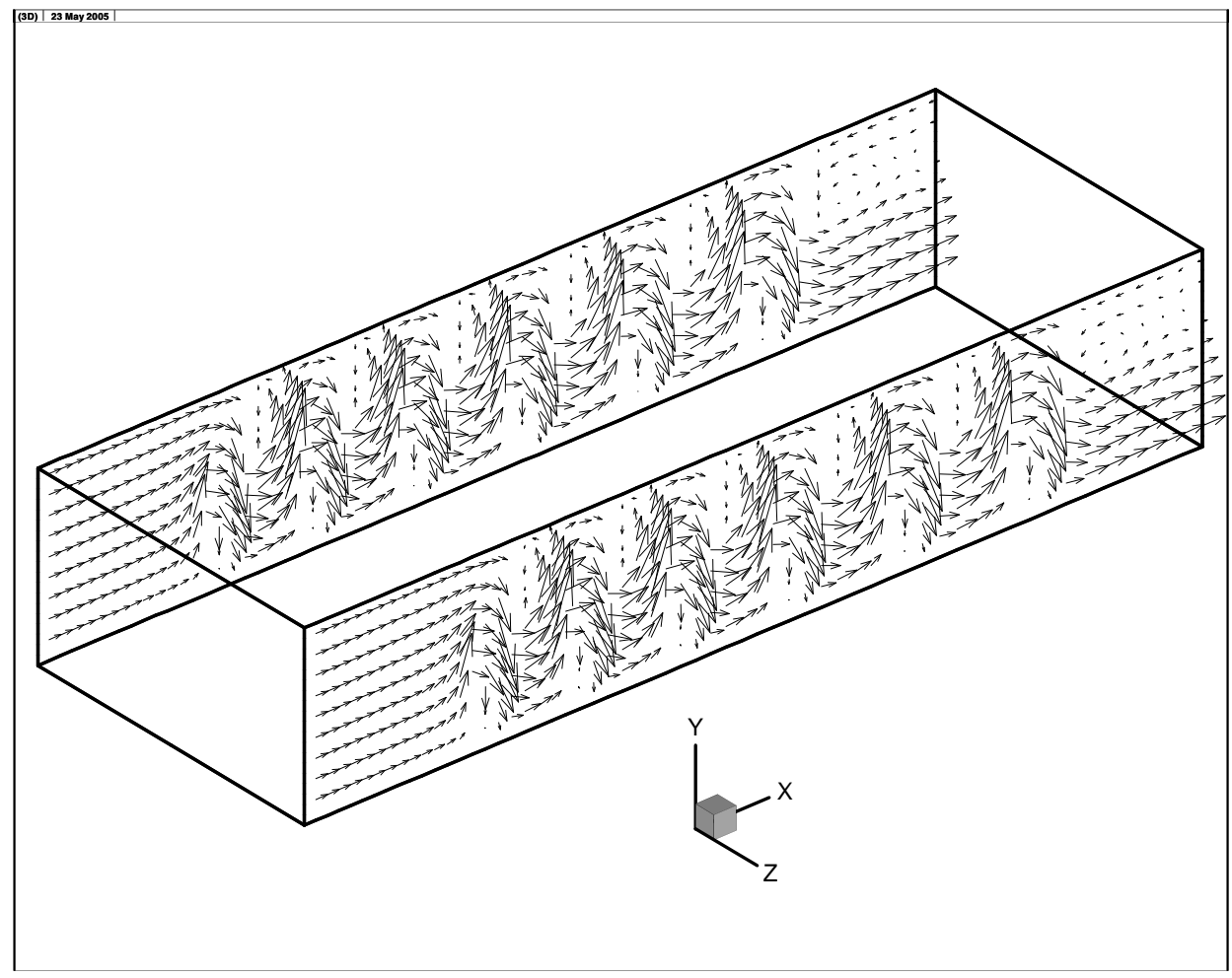

Figure 4. Velocity vector along the duct with staggered ribs for $v=10 \mathrm{~m} / \mathrm{s}$ and $\mathbf{H}_{\mathrm{r}}=\mathbf{7} \mathrm{mm}$ 

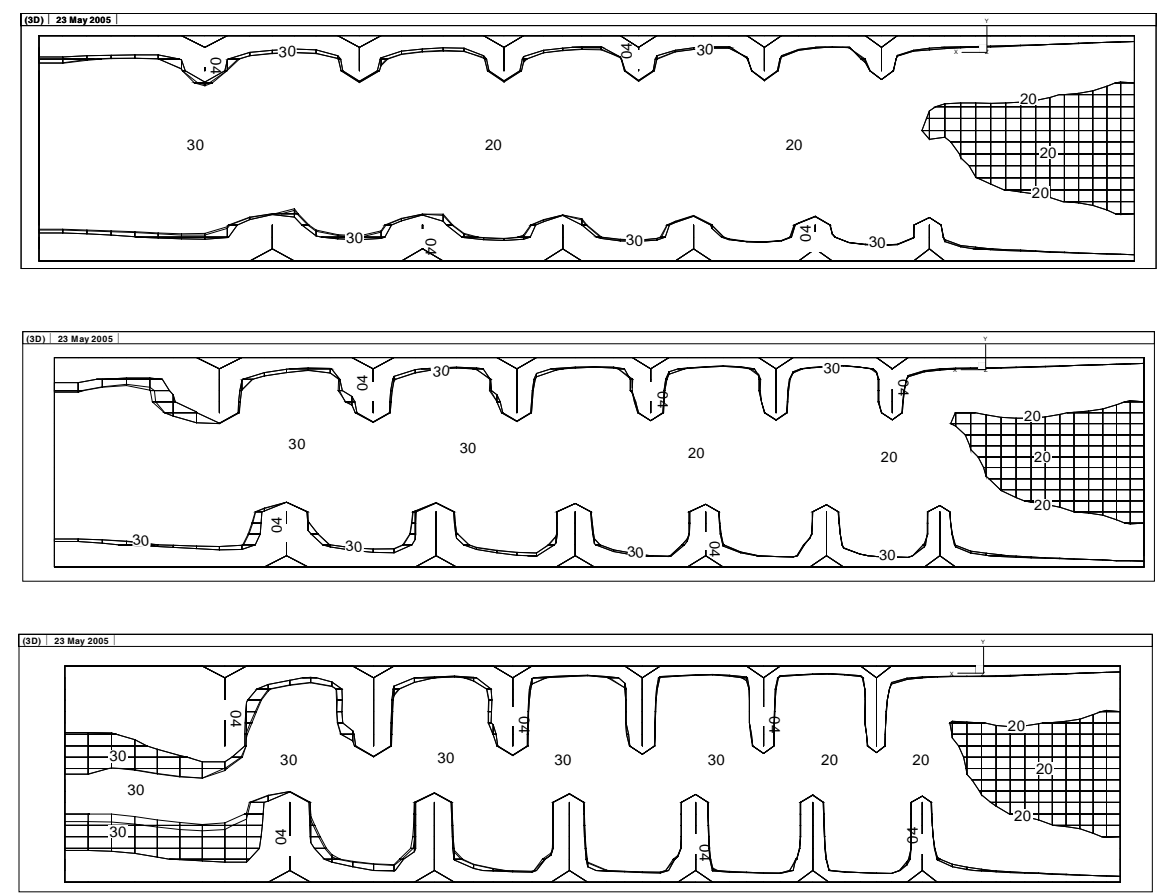

Figure 5. Isotherm contours along duct with lower ribs at $v=2.5 \mathrm{~m} / \mathrm{s}$, a) $H_{r}=3 \mathrm{~mm}$, b) $H_{r}=5 \mathrm{~mm}$, c) $H_{r}=7 \mathrm{~mm}$

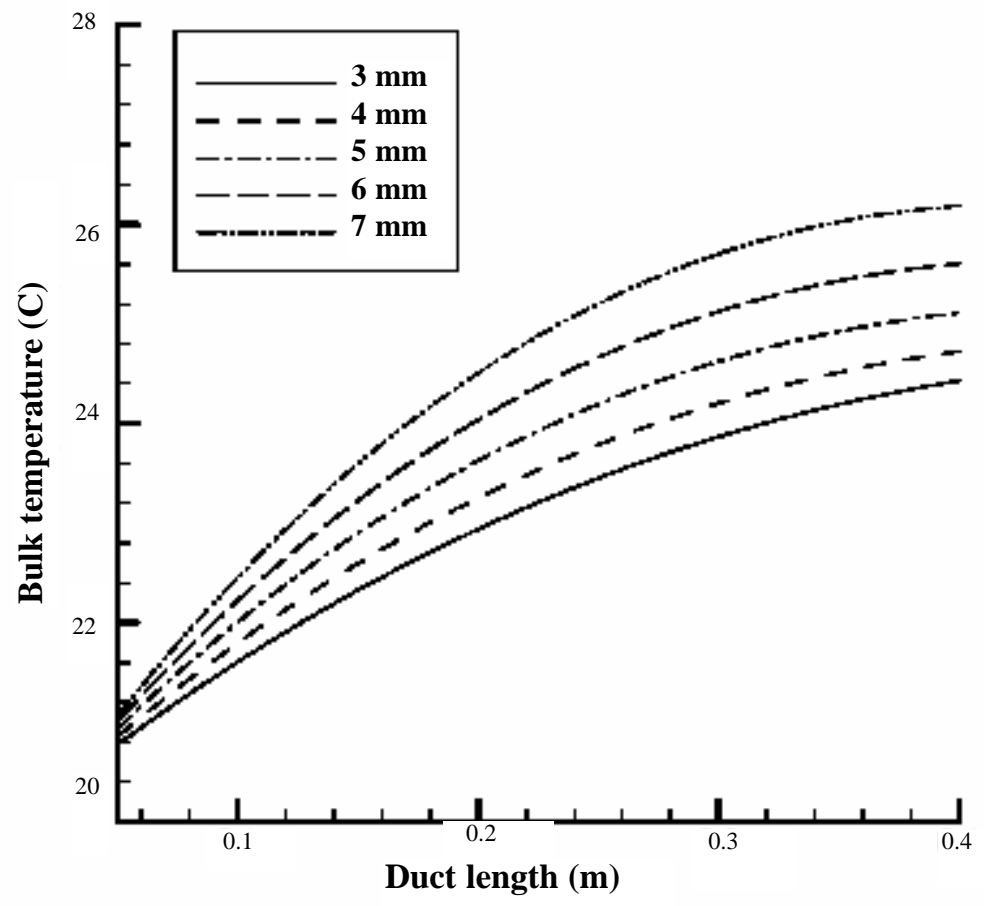

Figure 6. Bulk temperature variation with duct length for different rib heights for $v=5 \mathrm{~m} / \mathrm{s}$ and lower arrangement 


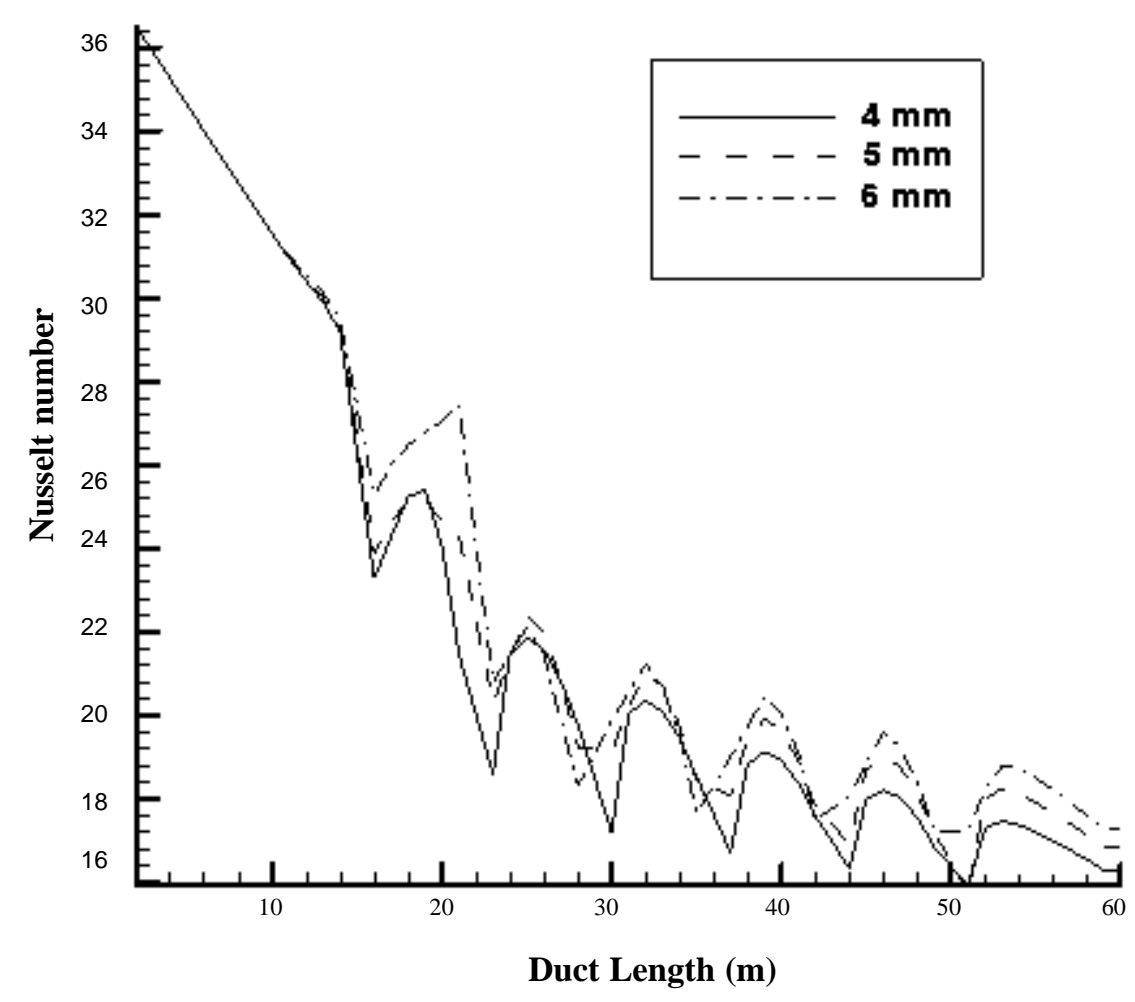

Figure 7. Variation of Nusselt number with duct length for lower arrangement and $\mathrm{v}=\mathbf{1 0} \mathrm{m} / \mathrm{s}$ and different ribs height

The following future work is recommended:

1. Studying further rib geometries like pitch and width.

2. Experimental study of cold air through ribbed duct.

\section{References}

Chang, S.W., Su, L.M. and Yang, T.L., 2004, "Heat Transfer in a Swinging Rectangular Duct with two Opposite Walls Roughened by $45^{\circ}$ Staggered Ribs," Int. J. of Heat and Mass Transfer, Vol. 44(11), pp. 287-305.

Gao, X. and Sunden, B., 2001, "Heat Transfer and Pressure Drop Measurements in Rib-roughened Rectangular Ducts," Experimental Thermal and Fluid Science, Vol. 24(1-2), pp. 25-34.

Han, J.C., 1988, "Heat Transfer and Friction Characteristics in Rectangular Channels with Ribs Turbulators," J. Heat Transfer, Vol. 110. pp. 321-328.

Hadhrami, L. A. and Chin Han, J.C., 2003, "Effect of Rotation on Heat Transfer in Two-pass Square Channels with Five Different Orientations of $45^{\circ}$ Angle Rib Turbulator," Int. J. of Heat and Mass Transfer, Vol. 46(4), pp. 653-669.
Kim, K. and Kim, S., 2001, "Numerical Optimization of Rib Shape to Enhance Turbulent Heat Transfer," Proceedings of the 2nd Int. Conference on Computational Heat and Mass Transfer.

Lee, C.K. and Moneim, S.A., 2001, "Computational Analysis of Heat Transfer in Turbulent Flow Past a Horizontal Surface with Two - Dimensional Ribs," Int. Communications in Heat and Mass Transfer, Vol. 28(2), pp. 161-170.

Onbasioglu, S. U. and Huseyin Onba, H., 2004, "On Enhancement of Heat Transfer with Ribs," Applied Thermal Engineering, Vol. 24(1), pp. 43-57.

Patanker, S. V., 1980, Numerical Heat Transfer and Fluid Flow, McGraw-Hill, New York.

Raisee, M. and Bolhasani, M.R., 2003, "Computation of Turbulent Flow and Heat Transfer in Passages with Attached and Detached Rib Array," Dept. of Mech. Engi., Faculty of Engineering, University of Tehran.

Taslim, M. E., Li, T. and Spring, S. D., 1998, "Measurements of Heat Transfer Coefficient and Friction Factors in Passages Rib-Roughened on All Walls," Transactions of ASME, Vol.120, pp. 564-570.

Tanda, G., 2004, "Heat Transfer in Rectangular Channels with Transverse and V-Shaped Broken Ribs," Int. J. of Heat and Mass Transfer, Vol. 47(2), pp. 229-243. 